\section{Rotavirus and Severe Childhood Diarrhea}

\section{Umesh D. Parashar," Christopher J. Gibson,* Joseph S. Bresee, ${ }^{*}$ and Roger I. Glass*}

Studies published between 1986 and 1999 indicated that rotavirus causes $\approx 22 \%$ (range $17 \%-28 \%$ ) of childhood diarrhea hospitalizations. From 2000 to 2004, this proportion increased to 39\% (range 29\%-45\%). Application of this proportion to the recent World Health Organization estimates of diarrhea-related childhood deaths gave an estimated 611,000 (range 454,000-705,000) rotavirus-related deaths.

$\mathrm{R}$ otavirus is the leading cause of diarrhea hospitalization among children worldwide (1). In 2003, we published an estimate of rotavirus-related deaths worldwide based on a review of the literature published from 1986 through 1999 on deaths caused by diarrhea and rotavirus hospitalizations in children (2). This review indicated that rotavirus accounted for $\approx 22 \%$ of hospitalizations for childhood diarrhea. By applying this fraction to an estimate of 2.1 million annual deaths from diarrhea, we calculated that rotavirus causes 440,000 annual deaths in children $<5$ years of age worldwide. This estimate was $\approx 50 \%$ of the 1985 estimate of 873,000 rotavirus deaths per year (3), and the decrease in estimated rotavirus-related deaths paralleled the decrease in deaths from diarrhea of all causes from an estimated 4.6 million deaths in 1982 to 1.6-2.5 million deaths in 2000 (4-6).

Recent studies suggest that as global deaths from childhood diarrhea decreased during the past 2 decades, the proportion of diarrhea hospitalizations attributable to rotavirus may have increased. For example, prospective, sentinel hospital-based surveillance of rotavirus disease in 9 Asian countries demonstrated a median rotavirus detection of $45 \%$ among children hospitalized with diarrhea (7), a figure that was considerably greater than the detection rates in previous studies from the same countries. Similarly, a more extensive study of 5,768 children hospitalized from 1998 through 2000 in 6 centers in Vietnam identified rotavirus in $56 \%$ of patients (8), a proportion that was more than twice the $21 \%$ detection rate reported among children hospitalized with diarrhea in a hospital in Hanoi, Vietnam, from 1981 to 1984 (9).

${ }^{*}$ Centers for Disease Control and Prevention, Atlanta, Georgia, USA
To systematically evaluate whether these recent reports are isolated observations or reflect a changing trend in the etiology of childhood diarrhea hospitalizations, we reviewed studies of rotavirus detection among children hospitalized with diarrhea published from 2000 through 2004 and compared the data with those of the previous review of studies published from 1986 through 1999.

\section{The Study}

Similar to the approach used in our previous review, we performed a computer search of the scientific literature (in English and other languages) published from January 2000 through June 2004 using the words rotavirus and the truncated stem rota-. We restricted the analysis to studies that met the following criteria: 1) were initiated after 1993; 2) were conducted for at least 1 full calendar year; and 3) examined rotavirus among at least 100 children $<5$ years of age hospitalized with diarrhea.

For each study, we determined the proportion of cases positive for rotavirus among children hospitalized with diarrhea. We plotted this proportion against the per capita gross national product (GNP) for the country in which the study was conducted. We then classified countries by per capita GNP into World Bank income groups (low, <US \$756; low-middle, US \$756-\$2,995; high-middle, US $\$ 2,996-\$ 9,265$; and high, >US $\$ 9,265$ ) (10), and calculated the median (interquartile range [IQR]) proportion of diarrhea hospitalizations attributable to rotavirus for each income group.

We next calculated an overall median detection rate by taking a weighted average of the median detection rates for each of the income groups. The weights assigned to each income group corresponded to the proportion of deaths from childhood diarrhea among countries in that income group as determined on the basis of our previous analysis (2): $85 \%$ in low-income countries, $13 \%$ in lowmiddle-income countries, $2 \%$ in high-middle-income countries, and $<1 \%$ in high-income countries. To estimate deaths from rotavirus disease among children, we multiplied the overall median detection rate of rotavirus among children hospitalized with diarrhea by a recent World Health Organization estimate of deaths from diarrhea among children worldwide (5).

We abstracted information from 41 studies that met all the inclusion criteria (online Appendix Table, available from http://www.cdc.gov/ncidod/EID/vol12no02/05-0006 _app.htm). Unlike the previous review of studies conducted for the period 1986-1999, in which the proportion of diarrhea-related hospitalizations attributable to rotavirus showed a distinct increasing trend with increasing income level, we found that the median detection rates increased only slightly with increasing income level (Figure 1). The median detection rate for rotavirus among children hospi- 


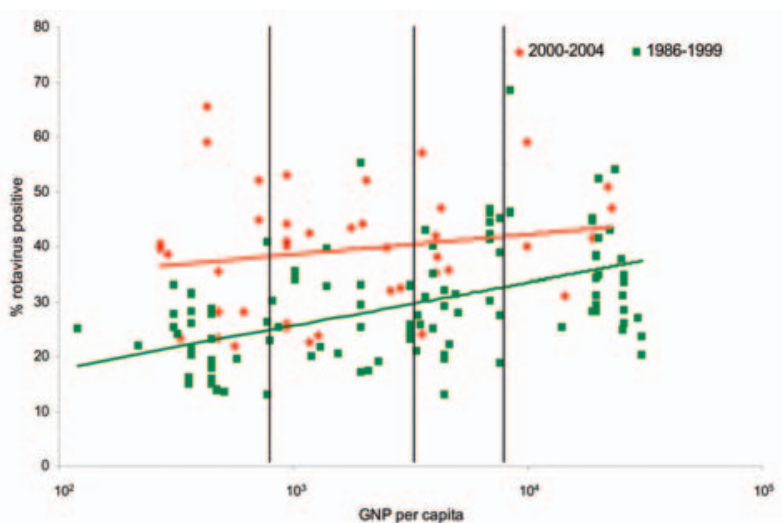

Figure 1. Percentage of severe diarrhea cases attributable to rotavirus for countries in different World Bank income groups, by per capita gross national product (GNP), for studies published in 1986-1999 and 2000-2004. GNP is in US dollars. Upper line, trend for 2000-2004; lower line, trend for 1986-1999.

talized with diarrhea was 39\% in studies conducted in lowincome countries, $40 \%$ for low-middle-income countries, $38 \%$ for high-middle-income countries, and $44 \%$ for highincome countries, for an overall weighted median estimate of $39 \%$ (Table).

If we multiply the greater median rotavirus detection rate of $39 \%$ (IQR 29\%-45\%) from this analysis by $1,566,000$ recently estimated childhood diarrhea deaths (5), we find that rotavirus causes $\approx 611,000$ childhood deaths (IQR 454,000-705,000). More than $80 \%$ of all rotavirus-related deaths were estimated to occur in lowincome countries of south Asia and sub-Saharan Africa (Figure 2).

\section{Conclusions}

Compared with results from studies published from 1986 to 1999, the proportion of diarrhea hospitalizations
Table. Percentage of diarrhea hospitalizations attributable to rotavirus for countries in different World Bank income groups, 1986-1999 and 2000-2004

\begin{tabular}{lcc}
\hline Income group & \multicolumn{2}{c}{$\begin{array}{c}\text { Median \% (interquartile range) of diarrhea- } \\
\text { associated hospitalizations due to rotavirus }\end{array}$} \\
\cline { 2 - 3 } Low & $1986-1999$ & $2000-2004$ \\
Low middle & $20(16-27)$ & $39(28-45)$ \\
High middle & $25(20-33)$ & $40(32-43)$ \\
High & $31(25-42)$ & $38(35-45)$ \\
Total* & $34(28-38)$ & $44(40-50)$ \\
\hline${ }^{*}$ The overall median was calculated by taking a weighted average of the \\
median rotavirus detection rate for each income group. The weights \\
applied to each group corresponded to that group's proportion of global \\
diarrheal deaths: 85\% for low-income countries, 13\% for low-middle- \\
income countries, $2 \%$ for high-middle-income countries, and <1\% for high- \\
income countries.
\end{tabular}

attributable to rotavirus appears to have increased between 2000 and 2004. This phenomenon likely reflects a relatively slower rate of decrease in hospitalizations for rotavirus compared with other causes of severe childhood diarrhea. This finding could be accounted for by several factors. First, interventions to improve hygiene and sanitation are likely to have a greater impact on diarrhea caused by bacterial and parasitic agents, which are transmitted primarily through contaminated food or water, unlike rotavirus, which is often spread from person-to-person. This hypothesis is supported by data from the United States (11) and Mexico (12), which showed that as diarrhea-related childhood deaths decreased dramatically in both countries; the decrease was greatest during the summer months when diarrheal diseases caused by bacteria are more prevalent. In both countries, diarrhea-related deaths in recent years have exhibited peaks only in the winter when rotavirus infections are common. Second, oral hydration therapy to replace loss of body fluids, which many regard as a major factor responsible for the decrease in diarrhea deaths (13), is often more difficult to successfully administer in children with severe vomiting (14), a common manifestation

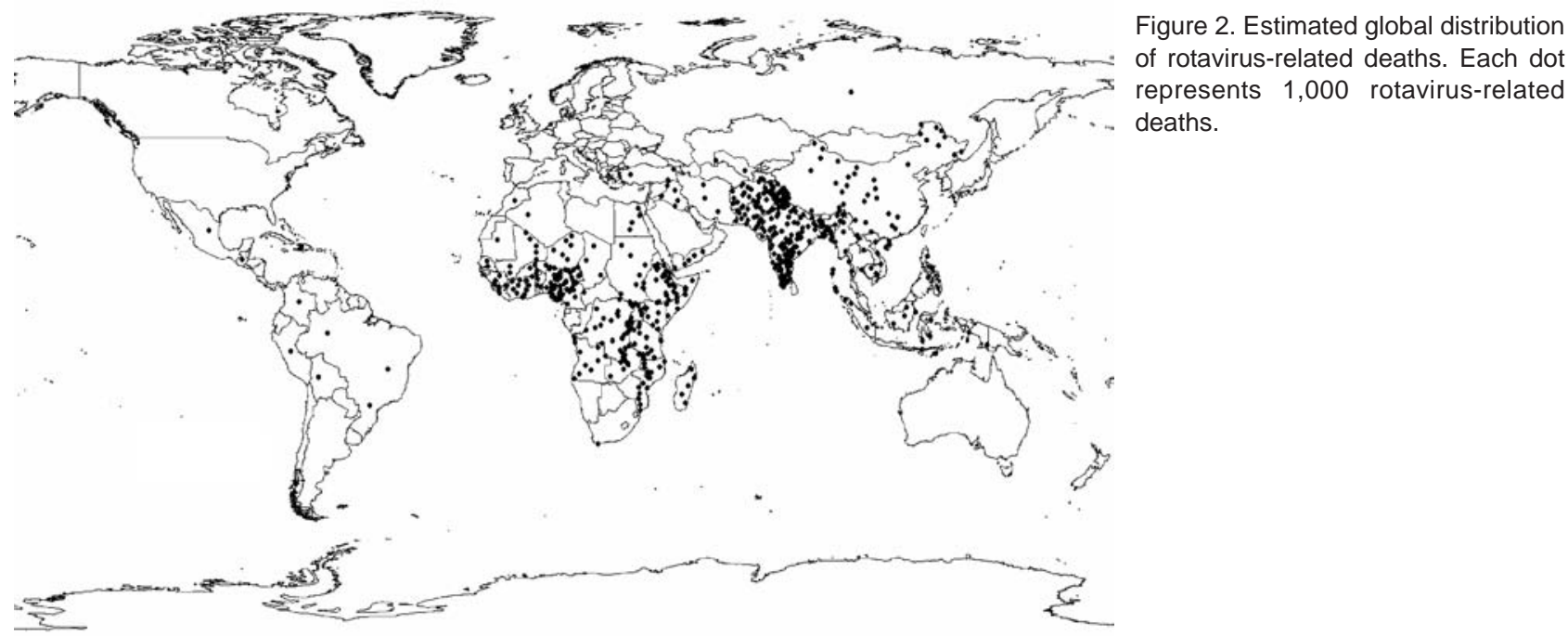


of rotavirus disease. Third, unlike antimicrobial therapies that are effective against some bacterial and parasitic agents, no specific treatment for rotavirus infection is available.

We have derived preliminary updated estimates of rotavirus-related childhood deaths on the basis of the findings of our review. Because we wanted to assess the most recent trends in rotavirus incidence, we examined a relatively limited number of studies published in the last 5 years, particularly from upper-middle- and high-income countries. However, these 2 income groups account for only a small fraction $(<5 \%)$ of all deaths from rotavirus disease, and the 28 studies available from low- and lowmiddle-income countries allowed for a reasonably robust analysis. Nevertheless, our findings should be updated as new data on rotavirus hospitalizations and updated estimates of childhood diarrhea deaths become available. In 2002, the World Health Organization published a generic protocol for hospital-based surveillance of rotavirus (15), and studies using this protocol are currently being conducted or planned in >30 countries in Asia, Africa, the Middle East, and Latin America. Data from these and other studies, particularly from countries such as India and China, which account for a large fraction of global rotavirus deaths, should be used to update our estimate of rotavirusrelated deaths and further refine it to develop country-specific figures. These data, together with information on effects and costs of rotavirus disease, will allow policymakers to assess the magnitude of the problem of rotavirus and the value of new vaccines that may soon be available.

Dr Parashar is a medical epidemiologist with the Respiratory and Enteric Viruses Branch, Division of Viral and Rickettsial Diseases, National Center for Infectious Diseases, Centers for Disease Control and Prevention. His research focuses on the epidemiology of viral gastroenteritis and respiratory infections and methods for their prevention and control.

\section{References}

1. Parashar UD, Bresee JS, Gentsch JR, Glass RI. Rotavirus. Emerg Infect Dis. 1998;4:561-70.
2. Parashar UD, Hummelman EG, Bresee JS, Miller MA, Glass RI. Global illness and deaths caused by rotavirus disease in children. Emerg Infect Dis. 2003;9:565-72.

3. Institute of Medicine. The prospects of immunizing against rotavirus. In: New vaccine development: diseases of importance in developing countries. Washington: National Academy Press; 1986. p. D131-D13-12.

4. Snyder JD, Merson MH. The magnitude of the global problem of acute diarrhoeal disease: a review of active surveillance data. Bull World Health Organ. 1982;60:605-13.

5. World Health Organization. The world health report 2003: shaping the future. Geneva: The Organization; 2003.

6. Kosek M, Bern C, Guerrant RL. The global burden of diarrhoeal disease, as estimated from studies published between 1992 and 2000. Bull World Health Organ. 2003;81:197-204.

7. Bresee J, Fang ZY, Wang B, Nelson EAS, Tam J, Soenarto Y, et al. First report from the Asian Rotavirus Surveillance Network. Emerg Infect Dis. 2004;10:988-95.

8. Van Man N, Van Trang N, Lien HP, Parch DD, Thanh NTH, Tu PV, et al. The epidemiology and disease burden of rotavirus in Vietnam: sentinel surveillance at 6 hospitals. J Infect Dis. 2001;183:1707-12.

9. Doan TN, Nguyen VC. Preliminary study on rotavirus diarrhoea in hospitalized children at Hanoi. J Diarrhoeal Dis Res. 1986;4:81-2.

10. World Bank Group. Classification of economies by income. 2000 [cited 2004 July 16]. Available from http://www.worldbank.org/data/ countryclass/classgroups.htm

11. Kilgore PE, Holman RC, Clarke MJ, Glass RI. Trends of diarrheal disease: associated mortality in US children, 1968 through 1991. JAMA. 1995;274:1143-8.

12. Villa S, Guiscafre H, Martinez H, Munoz O, Guiterrez G. Seasonal diarrhoeal mortality among Mexican children. Bull World Health Organ. 1999;77:375-80.

13. Victora CG, Bryce J, Fontaine O, Monasch R. Reducing deaths from diarrhea through oral rehydration therapy. Bull World Health Organ. 2000;78:1246-55.

14. Ahmed FU, Karim E. Children at risk of developing dehydration from diarrhoea: a case-control study. J Trop Pediatr. 2002;48:259-63.

15. Bresee J, Parashar U, Holman R, Gentsch J, Glass R, Ivanoff B, et al. Generic protocol for hospital-based surveillance to estimate the burden of rotavirus gastroenteritis in children under 5 years of age. In: Generic protocols for (i) hospital-based surveillance to estimate the burden of gastroenteritis in children and (ii) a community-based survey on utilization of health care services for gastroenteritis in children; field test version (WHO/V\&B/02.15). Geneva: World Health Organization; 2000. p. 1-44. Also available from http://www.who.int/ vaccine_research/diseases/rotavirus/documents/en

Address for correspondence: Umesh D. Parashar, Viral Gastroenteritis Section, Respiratory and Enteric Viruses Branch, Division of Viral and Rickettsial Diseases, National Center for Infectious Diseases, Centers for Disease Control and Prevention, Mailstop G-04, 1600 Clifton Rd, NE, Atlanta, GA 30333, USA: fax: 404-639-3645; email: uap2@cdc.gov

\section{emerging infectious diseases $\mathrm{O}$ hline}

\section{WWW.cdc.gov/eid}

To receive tables of contents of new issues send an email to listserve@cdc.gov with subscribe eid-toc in the body of your message. 